\title{
IN VIVO EFFECT OF IMMOBILISATION OF BONE MORPHOGENIC PROTEIN 2 ON TITANIUM IMPLANTS THROUGH NANO-ANCHORED OLIGONUCLEOTIDES
}

\author{
H. Schliephake ${ }^{*}$, J. Rublack ${ }^{1}$, N. Aeckerle ${ }^{1}$, A. Förster ${ }^{2}$, B. Schwenzer ${ }^{2}$, J. Reichert ${ }^{3}$ and D. Scharnweber ${ }^{3}$ \\ ${ }^{1}$ Dept. of Oral and Maxillofacial Surgery, George-Augusta-University, Göttingen, Germany \\ ${ }^{2}$ Technische Universität Dresden, Faculty of Mathematics and Sciences, Dept. of General Biochemistry \\ ${ }^{3}$ Technische Universität Dresden, Max Bergmann Centre of Biomaterials
}

\begin{abstract}
The aim of the present study was to test the hypothesis that immobilisation of bone morphogenic proteins on the surface of titanium implants through nano-anchored oligonucleotides can enhance peri-implant bone formation. Non-coding 60-mer DNA oligonucleotides (ODN) were anchored to the surface of custom made sandblasted acid etched (SAE) titanium screw implants through anodic polarisation, gamma-sterilised with a standard dose of 25 kGy, and were hybridised with complementary 30-mer strands of DNA oligonucleotides conjugated to rhBMP2. Blank SAE implants, SAE implants with nano-anchored ODN and SAE implants with nano-anchored ODN and non-conjugated rhBMP2 served as controls. The implants were inserted into the tibiae of 36 Sprague Dawley rats. Perforations at the head and the tip of the implants allowed for bone ingrowth. Bone ingrowth into perforations and bone implant contact (BIC) as well as bone density (BD) at a distance of $200 \mu \mathrm{m}$ from the implant surface were assessed after 1, 4 and 13 weeks. Implants with nano-anchored ODN strands hybridised with conjugated rhBMP2 exhibited enhanced bone ingrowth into the perforations and increased BIC after 1 week as well as increased BIC after 4 weeks compared to controls. No difference was seen after 13 weeks. Bone density around the outer implant surface did not differ significantly at any of the intervals. It is concluded that rhBMP2 immobilised on the surface of titanium implants through nano-anchored oligonucleotide strands can enhance bone implant contact. The conditions of sterilisation tested allowed for handling under clinically relevant conditions.
\end{abstract}

Keywords: Bone morphogenic proteins, oligonucleotides, titanium, sterilisation, controlled release, recombinant proteins, biofunctionalisation.

*Address for correspondence:

Prof. Dr. Dr. H. Schliephake

Dept. of Oral and Maxillofacial Surgery

George-Augusta-University

Robert-Koch-Str. 40, 37075 Göttingen, Germany

E-mail: schliephake.henning@med.uni-goettingen.de Telephone number: +49551398343

Fax number: +495513912653

\section{Introduction}

Osseointegration of titanium implants requires new bone tissue to be formed on the implant surface by the adjacent peri-implant bone. Under healthy conditions, this process is reliably efficient and leads to long term integration of the implant in the surrounding bone. Sites of implantation with compromised biology, however, may be unable to accomplish the required level of osteogenic activity leading to inferior quality of bone anchorage (Pan et al., 2000; McCracken et al., 2000; Keller et al., 2004). In order to enhance the process of peri-implant bone formation and implant anchorage, numerous approaches have been used to bind signalling molecules to the implant surfaces that are considered to enhance osteogenesis. Among the available growth factors, bone morphogenic proteins (BMPs) and vascular endothelial growth factor (VEGF) have been most frequently used to achieve this goal (Thorey et al., 2011; Ramazanoglu et al., 2013; Leknes et al., 2013; Mueller et al., 2011). However, massive overdosage in the use of recombinant BMP2 due to the lack of established low release systems has been discussed to lead to a number of complication in clinical applications such as excessive swelling, heterotopic ossification, seroma formation, pleural effusions and spinal complications (Beidas et al., 2013; Merrick et al., 2013; Shweikeh et al., 2014; Muchow et al., 2010).

The challenge of all approaches, using biologically active molecules in conjunction with titanium implants, is to achieve both reversible binding of growth factors to the metal surface and controlled delivery of active signals. Beyond simple adsorption, organic molecules such as phosphonate anchors (Adden et al., 2006a; 2006b), collagen and chondroitin sulphate (Schliephake et al., 2005, 2009; Stadlinger et al., 2008), heparin or chitosan in conjunction with silane or dopamine (Zheng et al., 2013; Kim et al., 2011, 2013; Lee et al., 2012) as well as polylactic acid (Choi et al., 2014; Thorey et al., 2011) have been employed to achieve anchorage of growth factors to the surfaces of titanium implants.

Regardless of which strategy has been used, growth factors bound to the surface of titanium implants during the fabrication process may become denaturalised and inactivated during sterilisation as the final step of production. Binding of growth factors to implant surfaces after sterilisation and immediately prior to insertion through adsorption using dip coating has been associated with a burst release that has shown negative effects for implant healing (Leknes et al., 2008; Wikesjö et al., 2008). Thus, a system for binding and controlled delivery of biologically active molecules would be desirable that can be applied "table side" immediately prior to 
insertion. Following the idea that the structure of DNA strands is resistant to $\gamma$-sterilisation under appropriate conditions, oligonucleotide DNA (ODN) strands have been recently explored for binding of biologically active molecules to titanium surfaces through hybridisation with complementary ODN strands conjugated to RGD peptides (Michael et al., 2009). Moreover, in vitro studies on binding and release of bone morphogenic protein 2 (rhBMP2) and vascular endothelial growth factor (VEGF165) conjugated to ODN strands have shown that growth factors are efficiently bound to the titanium surface through hybridising with complementary nano-anchored oligonucleotides and that biologically active molecules are released from these surfaces in a retarded fashion (Schliephake et al., 2012a, 2012b).

In order to utilise this principle for in vivo applications, conditions have to be identified that safeguard the integrity of the ODN anchor strands (AS) partially incorporated into the anodic oxide layers on the titanium surfaces during gamma sterilisation. In particular, the concentrations of reactive species produced due to the interaction of gamma quanta with water and oxygen as components of the sterilisation environment of the ODN have to be drastically reduced to prevent a degradation of the ASs.

The aim of the present study was therefore i) to identify conditions for $\gamma$-sterilisation of oligonucleotides nano-anchored to the surface of titanium implants that do not substantially reduce their ability to hybridise with complementary strands conjugated to bone morphogenic protein 2 (BMP2), and ii) to test the hypothesis that BMP2 bound to the surface of titanium implants through nanoanchored ODN strands under these conditions enhances peri-implant bone formation in vivo in a model.

\section{Materials and Methods}

\section{Sample disc and implant fabrication}

Custom made sample discs (Ø $14.7 \mathrm{~mm} \times 2 \mathrm{~mm})$ and selfcutting screw implants of $2.00 \mathrm{~mm}$ diameter and $5.00 \mathrm{~mm}$ length were fabricated from commercially pure titanium (KLS Martin, Tuttlingen, Germany). Two perforations of $0.8 \mathrm{~mm}$ diameter through the implant body at the tip and the head were created to allow for bone ingrowth (Fig. 1A). The surfaces of the implants and sample discs were prepared by sandblasting and subsequent acid-etching in 5.1 $\mathrm{M}$ hydrochloric acid and 4.6 M sulphuric acid solution for $300 \mathrm{~s}$ at $108^{\circ} \mathrm{C}$ (Schliephake et al., 2012a). Sixty-mer anchor strands and thirty-two-mer sacrificial strand 2 were synthesised by Thermo Fisher Scientific GmbH (Ulm, Germany). Thirty-one-mer oligonucleotides (GS-ODN) complementary to the anchor strands were synthesised by Thermo Fisher Scientific GmbH (Ulm, Germany).

Radio labelling of the GS-ODN was done over 3'-elongation with ${ }^{32} \mathrm{P}-\mathrm{dNTPs}$ by Hartmann Analytics GmbH (Braunschweig, Germany). For immobilisation of the ODN anchor strands (AS), an electrochemical setup was used that has already been described by Beutner et al., 2009. In short, for both the sample discs and the implants, a conventional three-electrode setup was used with a spiral gold wire acting as auxiliary electrode and
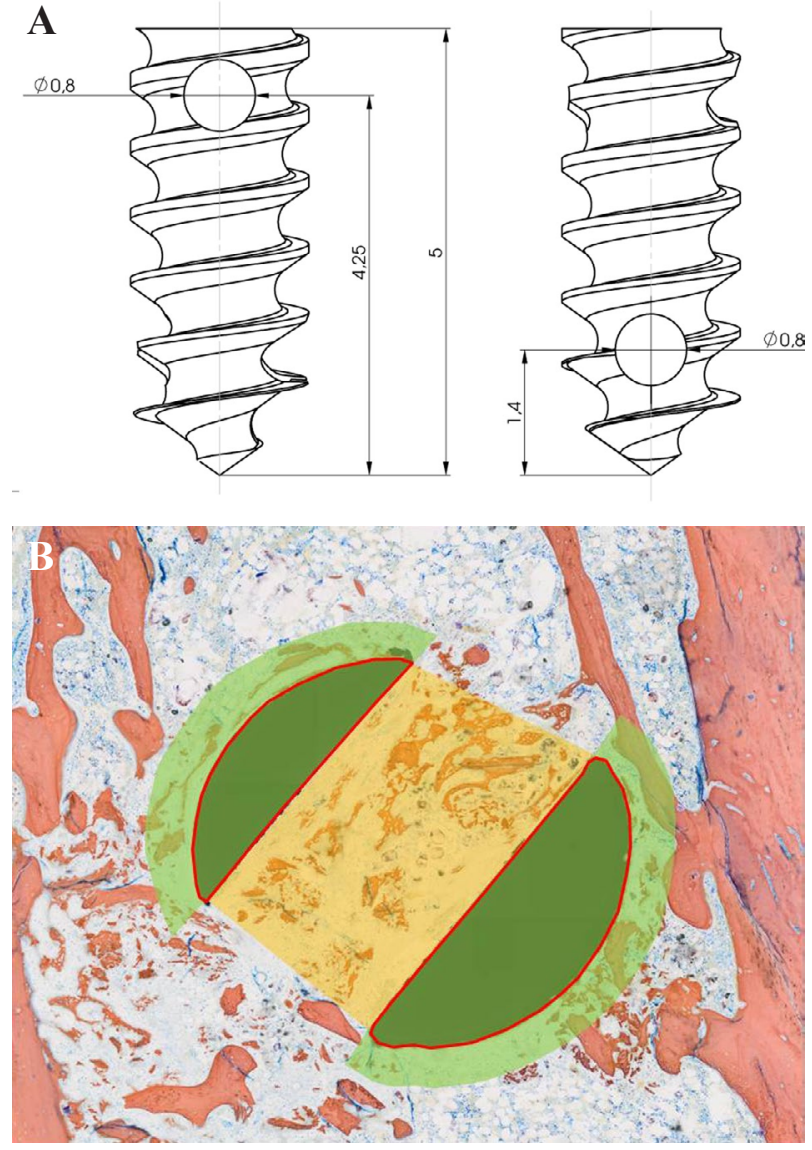

Fig. 1. A: Schematic drawing of the Ti-implant with location of perforations (units: $\mathrm{mm}$ ). B: Micrograph indicating assessment of the histomorphometric outcome parameters: Red: Implant surface; Light yellow: Area of assessment of bone formation inside the perforations, Light green: Area of peri-implant bone density measurement.

a saturated $\mathrm{Ag} / \mathrm{AgCl}$ reference electrode connected to the cell via a salt bridge made from a tube filled with agarose gel $\left(2 \% \mathrm{w} / \mathrm{v}\right.$ in $2 \mathrm{~mol} \mathrm{~L}^{-1}$ acetate buffer, $\left.\mathrm{pH} 4.0\right)$. Sample discs were treated mounted to the bottom (Ti) of a conical cell made from polyetherimide. Implants were screwed on to a custom made mount. Initial adsorption of the anchor strands on the sample discs was performed in $300 \mu \mathrm{L}$ each and on the implants in $100 \mu \mathrm{L}$ of $0.5 \mathrm{~mol} \mathrm{~L}^{-1}$ acetate buffer at $\mathrm{pH} 4.0$ with additional $5 \mathrm{~mol} \mathrm{~L}^{-1}$ ethanol for $15 \mathrm{~min}$. The electrolyte contained $800 \mathrm{nmol} \mathrm{L}^{-1} \mathrm{AS}$. After adsorption, $6 \mathrm{~mL}$ buffer (analogous to the adsorption electrolyte) were added to the cell and the anodic polarisation was started within $20 \mathrm{~s}$. The implants were placed in a conical teflon cell with the similar setup to that of the sample discs. The potentiostat/galvanostat (Voltalab 4.0, Radiometer Analytical, Lyon, France) was operated in galvanostatic mode with $11 \mathrm{~mA} \mathrm{~cm}^{-2}$ to ensure a polarisation time of approx. $3 \mathrm{~s}$ to reach a potential of $7.5 \mathrm{~V}_{\mathrm{Ag} / \mathrm{AgCl}}$. After polarisation, all samples were subsequently rinsed two times with $9 \mathrm{~mL}$ buffer inside the cell, followed by dipping the samples in sterile de-ionised water (SDI) $\mathrm{H}_{2} \mathrm{O}$ to remove the buffer. Subsequently, the samples were dried for $2 \mathrm{~h}$ at room temperature (RT) in the dark. 


\section{Sterilisation}

For the in vitro experiments, sample discs were sterilised using $\gamma$-radiation sterilisation $\left({ }^{60} \mathrm{Co}\right)$ with a minimum dose of 25 kGy (Synergy Health Radeberg GmbH, Radeberg, Germany). After ideal conditions for sterilisation have been identified, through evaluation of the sample discs for the ability of their AS to hybridise with complementary ODN strands (CS), sterilisation of the implants for in vivo experiments was performed with the same type of irradiation and dosage but under the conditions identified as ideal in the in vitro experiments.

\section{In vitro experiments}

Preservation of AS integrity during sterilisation

Immobilisation of AS was done according to the process described under electrochemical immobilisation and not incorporated AS were removed by storage of the samples for $24 \mathrm{~h}$ in $15 \mathrm{~mL}$ of PBS (per sample). The strategy for preservation of AS hybridisation ability during sterilisation aimed at two aspects of possible damage.

First, strategies were developed to minimise damage to AS by reactive oxygen species. Second, the AS were protected by using sacrificial ODN strands that were supposed to cover the AS, to reduce their contact to the underlying substrate surface, and become preferred subject to damaging effects of residual oxygen radicals.

The first approach was accomplished by employing different methods of drying and creating anti-oxidative variations in atmosphere during sterilisation and packing. Two strategies were used for drying: (i) Air drying: the samples were dried $2 \mathrm{~h}$ at room temperature in the dark, (ii) Phosphorus pentoxide (PPO) drying: sample discs were dried for $2 \mathrm{~h}$ at room temperature in the dark and then dried for $48 \mathrm{~h}$ over PPO under vacuum (3 kPa).

Three variations in combination with an anti-oxidative atmosphere during sterilisation and packing were used: (i) ethanol atmosphere: After drying of the sample discs, they were packed in a bottle $(1250 \mathrm{~mL})$ with $3 \mathrm{~mL}$ Ethanol, (ii) Wet Ar-Atm: The sample discs were transferred and sealed in alu peel bags (Früh Verpackungstechnik, Fehraltorf, Switzerland) in water containing argon-atmosphere, (iii) Ar-EtOH-Atm: After drying the sample discs were packed in $10 \mathrm{~mL}$ bottles and transferred in $1250 \mathrm{~mL}$ bottles with $1 \mathrm{~mL}$ ethanol (water free $>30 \mathrm{ppm}$ ) to realise an argon- ethanol-atmosphere. The transfer and packing took place in a glove box (MB 150B-G-II, MBraun, Garching, Germany).

For the second approach using sacrificial strands, two different designs of sacrificial strands (SCS) were investigated. SCS1 is identical to AS but not incorporated into the anodic oxide surface and SCS2 (32mer) has a sequence designed for minimal interaction with both, AS and CS (Table 1). All ODN strands were synthesised by Thermo Fisher Scientific GmbH (Ulm, Germany).

The effect of SCSs on the hybridisation behaviour of immobilised AS was investigated for three ranges of surface concentrations. For SCS1, the concentration range (a) between $4.5-7.5 \mathrm{pmol} / \mathrm{cm}^{2}$ was realised by skipping the removal step (storage of samples for $24 \mathrm{~h}$ in PBS; see above) the range (b) between $32.5-35.5 \mathrm{pmol} / \mathrm{cm}^{2}$ was realised by adding $50 \mu \mathrm{L}$ of $800 \mathrm{nM} \mathrm{SCS} 1$ solution on the sample. For SCS2, a concentration of $56 \mathrm{pmol} / \mathrm{cm}^{2}$ was realised by adding $50 \mu \mathrm{L}$ of $1.6 \mu \mathrm{M}$ SCS 2 solution on the sample after removing the not incorporated AS.

For analysis of hybridisation ability samples were placed in a 12 well plate and $100 \mu \mathrm{L}$ of the hybridisation solution was added containing $400 \mathrm{nM}$ GS-ODN in phosphate buffered saline (PBS, pH 7.4). Hybridisation was performed with $32 \mathrm{P}$-labeled CS (0.05-0.2\%) to quantify the surface density. The hybridisation took place for $1 \mathrm{~h}$ in the dark. Afterwards each sample was washed 3 times with $3 \mathrm{~mL} 1 \times$ PBS to remove strands not hybridised and dipped in water to remove salt residues. Radioactivity of all samples was measured using a passivated implanted planar silicon detector (PIPS-detector) based spectrometry (Canberra/Ortec, Meriden, USA / Oak Ridge, USA), from which the amount of labelled strand, and subsequently the GS-ODN surface density was calculated.

The reference, without sterilisation, was prepared according to the investigated conditions and stored at room temperature during the sterilisation process. Reference experiments, using non-sense GS-ODN, gave surface densities below $0.3 \mathrm{pmol} / \mathrm{cm}^{2}$ (results not shown) for all experimental conditions.

In total, eight sets of combinations of environments and SCSs were evaluated (Table 2). Because of a negative influence of amounts of SCS1 (b) on the hybridisation ability was anticipated (Sets 4 and 8), a removal step (storage of $2 \mathrm{~h}$ in $5 \mathrm{~mL} 1 \times \mathrm{PBS}$ ) was performed with

Table 1. Name, sequence and length of the used Oligodesoxyribonucleotides (ODN).

\begin{tabular}{|l|l|c|}
\hline \multicolumn{1}{|c|}{ Name } & \multicolumn{1}{|c|}{ Sequence } & $\begin{array}{c}\text { Length } \\
\text { in mer }\end{array}$ \\
\hline $\begin{array}{l}\text { AS: (anchor strand) two hybridisation } \\
\text { areas underlined } \\
\text { (SCS1) also used as sacrificial strand }\end{array}$ & $\begin{array}{l}\text { 5, }{ }^{2-P O} \text {-CCA AAC CCG TCA ATC AAG TCT ACA CTG TTC } \\
\text { CCAAC CCG TCA ATC AAG TCT ACA CTG TTC 3' }\end{array}$ & 60 \\
\hline $\begin{array}{l}\text { CS (complementary strand, } \\
\text { complementary to hybridisation areas } \\
\text { of AS) }\end{array}$ & 5' CAG TGT AGA CTT GAT TGA CGG GTT T 3' & 25 \\
\hline $\begin{array}{l}\text { NS (nonsense strand, not } \\
\text { complementary to AS, same base } \\
\text { content as CS) - control }\end{array}$ & 5' GCC ATA GTT TTT ATT AGG AGG TCG G 3' & 25 \\
\hline SCS2 (sacrificial strand) & 5' CCT CTT TCT CTT TCT CAT TTT CTT TCG TTC CC 3' & 32 \\
\hline
\end{tabular}


these sets after sterilisation prior to the hybridisation. Six samples were analysed per set.

\section{Evaluation of the efficacy of the sterilisation process}

For the investigation of sterility, sample discs were prepared as described above for immobilisation of anchor strands and dried two days over phosphorous pentoxide. Pseudomonas putida (ATCC 17390, Institute for Microbiology, University of Hohenheim, Germany) were cultivated for $24 \mathrm{~h}$ in nutrient broth $(0.3 \%$ beef extract, $0.5 \%$ yeast extract, $0.5 \%$ Peptone and $0.5 \% \mathrm{NaCl}$, $\mathrm{pH} 7$ ) before added to the samples. $50 \mu \mathrm{L}$ of the cultivated Pseudomonas putida (corresponding to $25 \times 10^{6} \mathrm{CFU}$ ) were added to the samples and dried. Then the samples were packed in alu peel bags under water containing argon-atmosphere (glove bag) and sterilised with $25 \mathrm{kGy}$. Following, each sample was placed in $3 \mathrm{~mL}$ nutrient medium and incubated for $12 \mathrm{~h}$ on a shaker $(150 \mathrm{rpm})$. The samples were rinsed and the solution was plated. The optical density of the solution was measured, at $600 \mathrm{~nm}$, to determine the colony forming unites (CFU) of the plated solution. Pure nutrient broth was used as a control.

Conjugation of complementary oligonucleotides to rhBMP2 (BMP-ODN) and hybridisation of BMP-ODN conjugates to nano-anchored $A S$

For both in vitro release measurements as well as in vivo evaluation, conjugation of rhBMP2 (E. coli) (Reliatech, Braunschweig, Germany, product code: http://www.reliatech.de/fileadmin/ds/ch/200-002.pdf) with complementary oligonucleotides (CS) was done, by using disuccinimidyl suberate (DSS) as linker molecule. In a first step the aminomodified GS-ODN was activated with DSS in $1 \mathrm{mM}$ acetate buffer $\mathrm{pH}$ 4.0. The excess DSS was separated using an illustra NAP-10 column (GE Healthcare, Freiburg, Germany). The DSS-activated CS-ODN was mixed with rhBMP2 in phosphate buffered saline (PBS) containing $2 \mathrm{M}$ sodium chloride $\mathrm{pH} 7.4$ and incubated at room temperature for at least $18 \mathrm{~h}$.

According to the assessment of preservation of AS integrity during sterilisation, surfaces sterilised under the conditions of set 7 were used for the in vitro evaluation of binding and release. Loading of titanium surfaces was performed as described previously (Schliephake et al., 2012a). For each disc, $100 \mu$ L of BMP-ODN solution was prepared by mixing $10 \mu \mathrm{L}$ of PBS, $80 \mu \mathrm{L}$ of pure water and $10 \mu \mathrm{L}$ of conjugated growth factor solution containing $715 \mathrm{ng}$ of rhBMP2. The volumes of $100 \mu \mathrm{L}$ were pipetted onto the discs and left for hybridisation in a dark chamber at room temperature for $1 \mathrm{~h}$. Care was taken to accommodate the complete volume on the disc surface. Subsequently, the specimens were washed three times in PBS. The amount of BMP that was washed away was measured using a custom made commercially produced sandwich ELISA (Dr. Mark Hennies, Euskirchen, Germany). Four discs were evaluated and measurements were performed in duplicate.

In vitro release and bioactivity of growth factor conjugates The release of conjugated and non-conjugated rhBMP2 was assessed as described previously (Schliephake et al., 2012a). Discs were placed in cell culture medium
Table 2. Sterilisation conditions drying and additives for the different investigated.

\begin{tabular}{|l|l|l|}
\hline Set & Drying & Addition \\
\hline 1 & air dried & None \\
\hline 2 & air dried & Ethanol \\
\hline 3 & PPO & wet Ar-Atm, SCS1(a) \\
\hline 4 & PPO & wet Ar-Atm, SCS1(b) \\
\hline 5 & PPO & wet Ar-Atm, SCS2 \\
\hline 6 & PPO & dry Ar-EtOH-Atm \\
\hline 7 & PPO & dry Ar-EtOH-Atm, SCS1(a) \\
\hline 8 & PPO & dry Ar-EtOH-Atm, SCS1(b) \\
\hline
\end{tabular}

(DMEM, $1 \mathrm{~g}$ Glc/L, Biochrom, Berlin, Germany) in BSA coated 24-well plates. The medium was collected and replaced after, $3 \mathrm{~h}, 24 \mathrm{~h}, 3 \mathrm{~d}, 7 \mathrm{~d}, 14 \mathrm{~d}$ and $21 \mathrm{~d}$. The amount of released BMP2 was assessed using the custom made commercially produced sandwich ELISA mentioned above. The minimum detectable amount was $100 \mathrm{pg} / \mathrm{mL}$ BMP2. Four discs from each group were evaluated at each interval for the release experiments. All measurements were performed in duplicate.

In order to test whether the conjugated rhBMP2 differed in its osteogenic activity from the non-conjugated rhBMP2, biological activity was evaluated by induction of Alkaline Phosphatase (AP) in C2C12 cells (www. dsmz.de): $7.5 \times 10^{5}$ cells were seeded and grown in $1 \mathrm{~mL}$ Medium (DMEM, 1.0 g Glc, 10 \% FCS (Biochrom, Berlin, Germany) for $72 \mathrm{~h}$ after which the control medium, medium containing released non-conjugated BMP2/ conjugated BMP2, respectively, were added. After $72 \mathrm{~h}$, AP activity was assessed after ultrasound induced cell lysis (Bandelin, Berlin, Germany) in $200 \mu \mathrm{L}$ buffer (1\% NP-40 in ALP buffer, Sigma, www.sigmaaldrich.com) and subsequent centrifugation (5 $\mathrm{min} / 1000 \mathrm{rpm})$ using 4-Nitrophenylphosphate ( $2 \mathrm{mg} / \mathrm{mL}$, Sigma) as substrate. Measurements were made after 15 min reaction time in a dark chamber using an ELISA reader (Tecan Genios plus, Tecan, www.tecan.com) at $405 \mathrm{~nm}$. Values were calculated as turnover of $\mathrm{pNPP}(\mu \mathrm{mol} / \mathrm{min} \times \mathrm{mg}$ protein $)$. Measurements were made in triplicate.

\section{In vivo experiments}

According to the results of the in vitro evaluations, implants for the in vivo experiments were sterilised under the conditions of the sterilisation protocol of set 7 .

\section{Hybridisation of BMP-ODN conjugates to nano-anchored AS on test implants}

For each test implant, $100 \mu \mathrm{L}$ of BMP-ODN solution containing 740 ng rhBMP2 conjugate to ODN strands were prepared by mixing $10 \mu \mathrm{L}$ of $10 \times$ PBS, $80 \mu \mathrm{L}$ of pure water and $10 \mu \mathrm{L}$ of conjugated growth factor solution containing $740 \mathrm{ng}$ of rhBMP2. The volumes of $100 \mu \mathrm{L}$ were pipetted onto the implants and left for hybridisation in a dark chamber at room temperature for $1 \mathrm{~h}$. Care was taken to accommodate the complete volume on the implant surface and inside the perforations. Subsequently, the specimens were washed four times in PBS. 
Two types of control implants were used: i) implants with blank SAE surfaces and ii) implants with SAE surfaces with nano-anchored ODN anchor strands (AS) but without hybridisation to oligonucleotide-growth factor conjugates. This resulted in four groups:

Group 1: Implants with blank sandblasted acid-etched (SAE) surfaces.

Group 2: Implants with SAE surfaces with nano-anchored AS.

Group 3: Implants with SAE surface with nano-anchored AS with non-conjugated rhBMP2.

Group 4: Implants with SAE surface with nano-anchored AS that were hybridised with complementary oligonucleotides conjugated to rhBMP2 as described above.

\section{Implant placement}

The implants were placed into the tibia heads of 36 female Wistar rats (average weight 449.1 g, Charles River, Sulzfeld, Germany). All surgical procedures, housing and animal care were carried out according to the regulation of the State of Lower Saxony (Reg. No. 10/0224). Implants from Groups 1 and 2 were placed into 18 animals into the right and left leg, respectively. Implants from Groups 3 and 4 were placed into one leg of another 18 animals each. For implant placement, the anterior edge of the tibial plateau was exposed through a straight skin incision and the implants were inserted self-cutting, perpendicular to the long axis of the tibia through the tibia head engaging the cortical bone with both the apex and the head of the implants. All implants achieved primary stability. After wound closure in layers, the animals were allowed to move freely and feed themselves with water and pellets ad libitum.

\section{Histologic Processing}

After 1, 4 and 13 weeks, 6 implants from each group were removed together with the surrounding bone and fixed immediately in $3 \%$ formaldehyde. After dehydration, the bone blocks containing the implants were embedded into methylmethacrylate (Technovit Heraeus Kulzer, Hanau, Germany). Serial thick-section specimens (15-20 $\mu \mathrm{m}$ thickness, approx. distance $400 \mu \mathrm{m}$ ) were produced perpendicular to the long axis of the implants, according to Donath (1985), and stained with alizarine / methylene blue. Specimens were serially recorded by automatic scanning (Olympus dotSlide ${ }^{\circledR}$, Olympus Life Science, Hamburg, Germany). All six implants were included into the evaluation of each group. Four sections through the perforations of each implant (i.e. 24 cross sections per group) were analysed, assessing three outcome parameters: Bone density of newly formed bone inside the perforations (i.e. volume of bone tissue grown into the perforations as percentage of the cross sectional area of the perforations), the percentage of implant surface covered by bone tissue and the bone density in an area of $200 \mu \mathrm{m}$ surrounding the outer implant surface were assessed semi-automatically on the digitised images through pixel counting using image analysis software (Adobe Photoshop CS5, Adobe Systems GmbH, München) (Fig. 1B). One calibrated blinded examiner evaluated all specimens. Average values were calculated for each implant from measurements on individual cross sections, i.e. the unit of evaluation was the individual implant. Average values for each group were then calculated from the results of the respective implants and submitted to statistical evaluation.

Due to remodelling of the tibial bone during the observation period, the portions of the implants in contact with cortical and cancellous bone, respectively, varied within the groups after 1 week and 1 month. This was addressed by separate evaluation of peri-implant bone formation around those implant parts in cortical bone and those in cancellous bone for these intervals.

\section{Statistics}

Analysis of data distribution (SPSS Statistics 20.0, http:// support.spss.com) exhibited a considerable departure from Gaussian distribution with skewness values of -0.80 , 2.698 and 0.999 (for $\mathrm{BIC}, \mathrm{BD}_{\text {perf }}$ and $\mathrm{BD}_{\text {ext }}$ ) and kurtosis values of $-1.385,0.198$ and 0.201 , respectively. Hence, it was decided to use non-parametric tests for statistical evaluation.

Wilcoxon tests (SPSS Statistics 20.0, http://support. spss.com) were used to test differences in both in vitro release and in parameters of peri-implant bone formation between the different groups and Kruskal-Wallis tests were used to test differences over time both at a level of significance of $p<0.05$.

\section{Results}

\section{In vitro results}

\section{Hybridisation ability of AS after sterilisation}

The effect of (i) different drying procedures, (ii) the addition of ethanol and (iii) the addition of different concentrations and types of sacrificial complementary strands (SCS) on the availability of AS for hybridisation with complementary ODN strands (CS) after sterilisation is shown in Fig. 2A.

The hybridisation ability of the incorporated AS decreased to $1 \pm 0.4 \%$ after sterilisation without protective measures (set 1). The effect of storage of the samples in an ethanol atmosphere during sterilisation had no measurable protective effect without an additional drying processing. Only $1.7 \pm 0.6 \%$ of the AS was able to hybridise CS after sterilisation (set 2). The combination of argonethanol-atmosphere with a drying process (phosphorus pentoxide drying (PPO)) showed an increase to $41 \pm 20 \%$ hybridisation ability (set 6).

For the introduction of SCS similar values of about $20 \%$ to $30 \%$ hybridisation ability were obtained for SCS1 (a) (lower concentration) and SCS2 under the conditions drying over phosphorus pentoxide and packing in wet argon-atmosphere maintains only (sets 3 and 5). Up to $80 \%$ hybridisation availability could be obtained for SCS1 (b) applied with 32.5-35.5 $\mathrm{pmol} / \mathrm{cm}^{2}$ combined with drying over phosphorus pentoxide and packing in dry argon-ethanol-atmosphere (set 4). Drying over phosphorus pentoxide in combination with packing in a dry argonethanol-atmosphere without sacrificial strands (set 6) could preserve only $40 \%$ of the hybridisation ability of the AS. 
A

Percentage of hybridised anchor strands after sterilisation

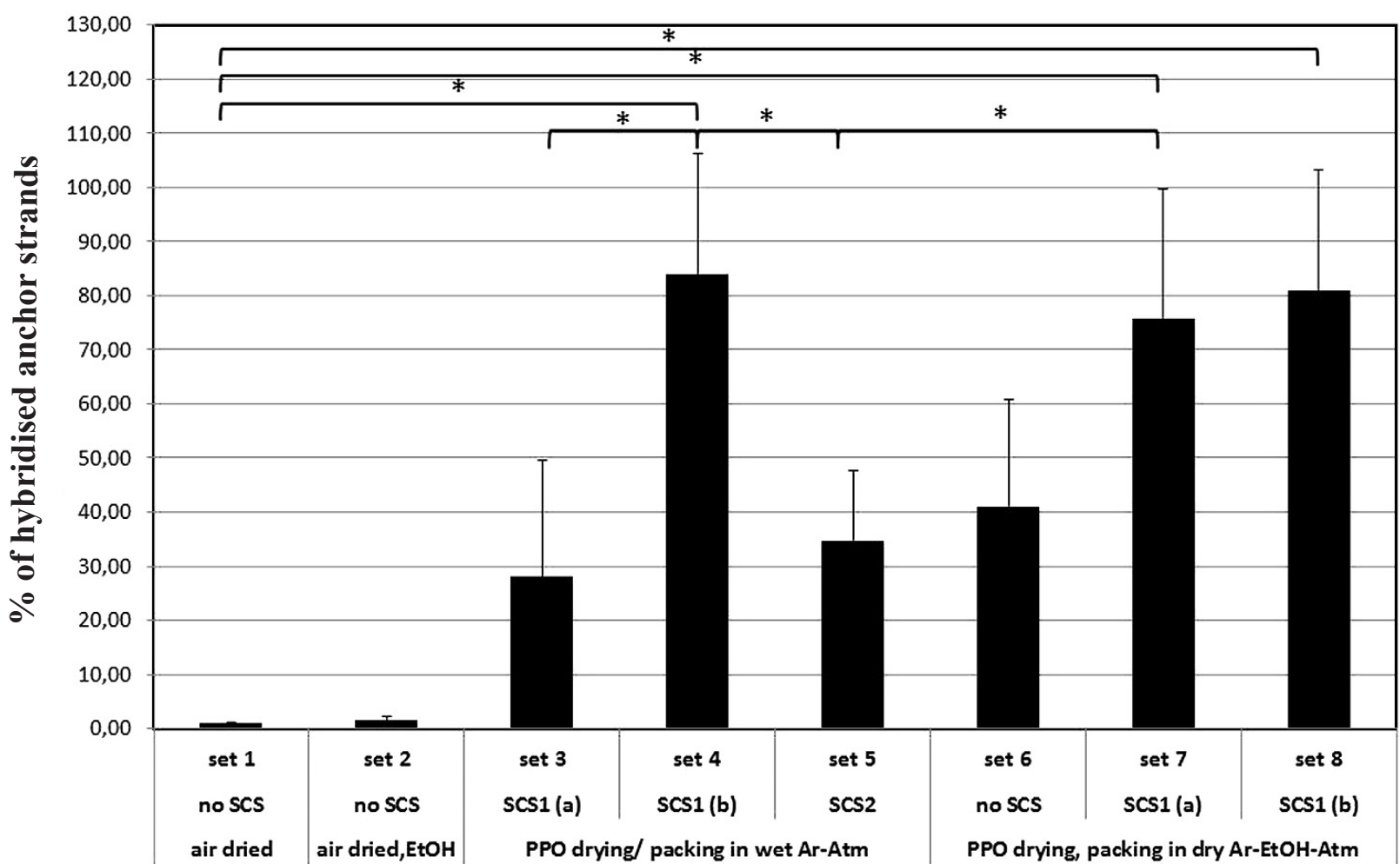

B

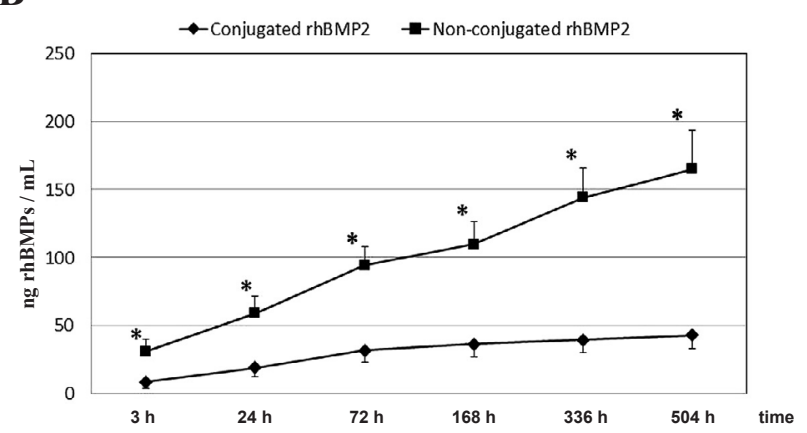

C Bioactivity of rhBMP2

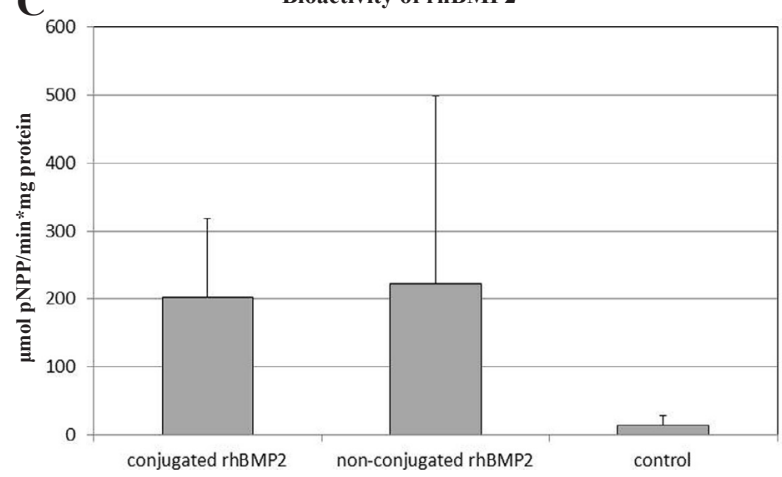

Fig. 2. A: AS (anchor strand) availability for hybridisation with CS (complementary strand) after sterilisation under different environmental conditions and for combinations of different SCS (sacrificial strands) (type and surface concentration) calculated as percentage of not sterilised samples (mean values, standard deviation); Surface concentrations SCS1 (a) 4.5-7.5 pmol $/ \mathrm{cm}^{2}$; SCS1 (b) $32.5-35.5 \mathrm{pmol} / \mathrm{cm}^{2}$; SCS2 $56 \mathrm{pmol} / \mathrm{cm}^{2}$. Conditions: drying (over PPO (phosphorus pentoxide)), argon-atmosphere (Ar-Atm) and ethanol additions (liquid ethanol (EtOH) or ethanol-atmosphere (EtOH-Atm)). ${ }^{*} p<0.05, n=6$ per set. B: in vitro release of conjugated and non-conjugated rhBMP2 from the titanium surface with nano-anchored AS (anchor strands) and SCS (sacrificial strands), (mean values, standard deviation, $n=4$ pairs of samples, dual measurements per sample) ( $p$-value $=0.029$ for each pair). C: Biological activity (alkaline phosphatase) of conjugated and non-conjugated rhBMP2 (mean values, standard deviation, $n=3$ samples per group, dual measurements per sample).

The same conditions, combined with sacrificial strands nearly doubled the hybridisation availability to about $80 \%$ irrespective of the concentration of SCS1 (sets 7 and 8).

\section{Sterility after Sterilisation}

Table 3 shows the quality of the gamma sterilisation process for samples with SCS1 (32.5-35.5 pmol/ $\left.\mathrm{cm}^{2}\right)$ dried over phosphorous pentoxide and packed in a wet argonatmosphere. For samples infected with $25 \times 10^{6} \mathrm{CFU}$ Pseudomonas putida, no remaining bacterial activity could
Table 3. CFU and OD of Pseudomonas putida after sterilisation.

\begin{tabular}{|l|c|c|c|}
\hline & sample & sample & sample \\
& $\mathbf{1}$ & $\mathbf{2}$ & $\mathbf{3}$ \\
\hline CFU/mL of the plated solution & 0 & 0 & 0 \\
\hline OD of the washing solution & -0.001 & 0.001 & -0.001 \\
\hline
\end{tabular}



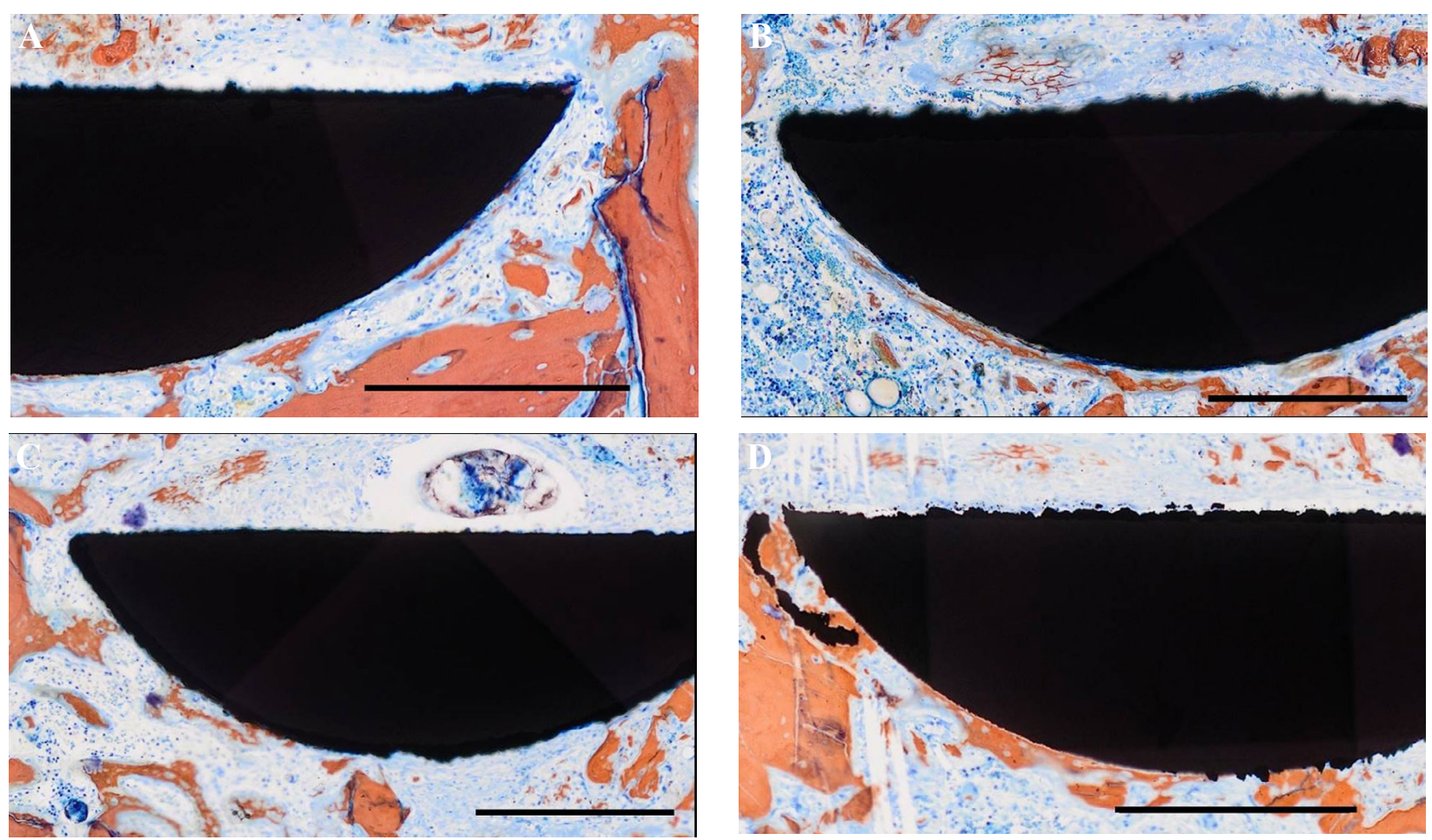

Fig. 3. Micrographs of implant cross sections in cancellous tibial bone after 1 week (alizarine / methylene blue, Scale Bar: $500 \mu \mathrm{m})$ A: Group1 (SAE surface) exhibiting early bone formation with osteoid seams surrounded by bone debris; B: Group 2 (SAE \& AS surface) with commencing formation of mineralised tissue close to the implant surface; C: Group 3 (SAE \& AS \& non-conj. BMP) Early bone formation with scarce contact to the implant surface; D: Group 4 (SAE \& AS \& conj. BMP) surface showing direct bone apposition on the implant surface. (SAE: sandblasted \& acid etched surface; SAE \& AS:, SAE \& AS \& conj. BMP: sandblasted \& acid etched surface plus oligonucleotide anchor strands with hybridised BMP2-conjugates)

be detected after the sterilisation and $12 \mathrm{~h}$ incubation in nutrient medium. Similar results were obtained for the wash solution.

Loading, in vitro release and bioactivity of growth factor conjugates

Evaluation of loading of conjugated and non-conjugated rhBMP2 exhibited that 515.2 ng (SD 49.3) of conjugated rhBMP2 and $560.9 \mathrm{ng}$ (SD 43.3) of non-conjugated rhBMP2, respectively, have been immobilised on the titanium surfaces with AS (anchor strands) and SCS (sacrificial strands). Release curves demonstrated that the delivery of non-conjugated rhBMP2 from the titanium surfaces was significantly higher than the conjugated rhBMP2 during the entire observation period of three weeks (Fig. 2B) ( $p=0.029)$. The assessment of biological activity exhibited comparable turnover of pNPP for both non-conjugated and conjugated rhBMP2 (Fig. 2C).

\section{In vivo results}

All animals survived and no implant was lost. Healing was uneventful and all implants were submitted to histologic and morphometric analysis.

\section{Histology}

Early bone formation and organisation of bone debris was visible after 1 week along the implant surface and at the entrance of the perforations of implants from all groups
(Figs 3 A through C). In general, implant parts located in the cortical layer exhibited more pronounced osteoconductive bone formation than those located in cancellous bone. The latter showed distinct differences in the patterns of bone formation on the surface: Implants from Group 1 and 2 exhibited formation of mineralised matrix close to but not in immediate contact with the titanium surface. Higher magnification revealed that there was a small but almost continuous non-mineralised layer between the surface and the newly formed mineralised bone matrix on implants with SAE and SAE and AS surfaces (Figs 3A and B). Implants with nano-anchored AS strands and hybridised conjugated rhBMP2 on the surface had a mineralised layer directly deposited on the surface in most of the areas with osteoblasts lying on top of this layer (Fig. 3D).

After 1 month, bone formation on the surface had increased and the difference between implant parts in cortical and cancellous bone had levelled off. Bone remodelling had smoothed the contours of the newly formed bone and had removed all debris. Again, there was a distinct difference in the features of bone laid down on the surfaces of the implants from the different groups. Implants from Groups 1 and 2 had small islands of bone formed on the surface that appeared to undergo remodelling and were partially separated from the implant surface by cells and organic matter (Figs. 4 A and B). Implants from Group 4 again showed a more contiguous layer of bone in immediate contact with the implant surface (Fig. 4D). 

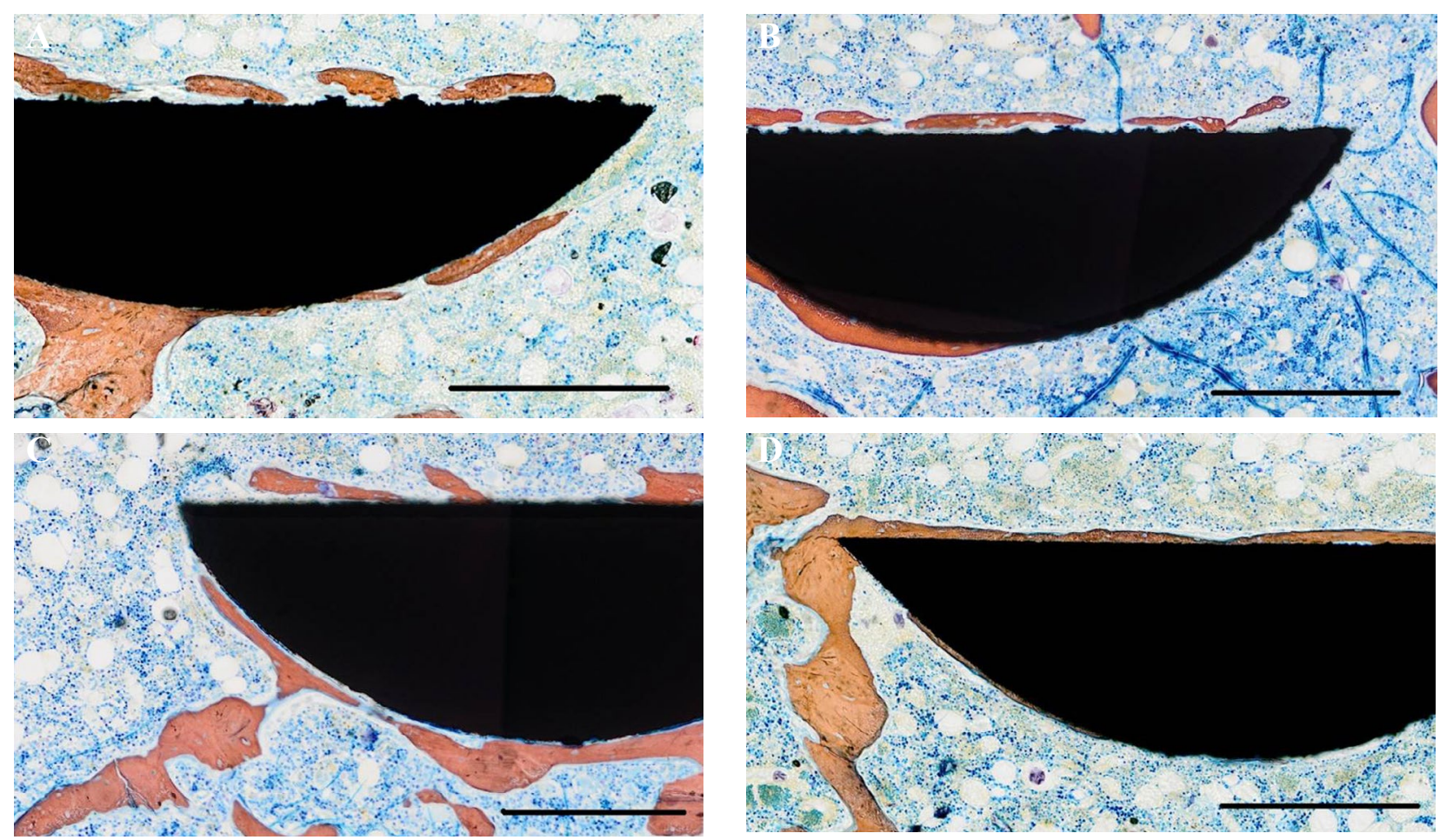

Fig. 4. Micrographs of implant cross sections in cancellous tibial bone after 4 week (alizarine / methylene blue, Scale Bar: $500 \mu \mathrm{m})$ A: Group1 (SAE surface) small island of bone formation with intervening organic matter between mineralised tissue and implant surface; B: Group 2 (SAE \& AS surface) with similar features in the area of newly formed bone; C: Group 3 (SAE \& AS \& non-conj. BMP) Thin bone formation following the contour of the implant surface with intervening non-mineralised layer; D: Group 4 SAE \& AS \& conj. BMP surface showing direct bone implant contact and osteocytes embedded into a thin layer of mineralised tissue directly on the implant surface. (SAE: sandblasted \& acid etched surface; SAE \& AS:, SAE \& AS \& conj. BMP: sandblasted \& acid etched surface plus oligonucleotide anchor strands with hybridised BMP2-conjugates)

After 3 months, no differences were seen between the three groups in morphology of peri-implant bone. Implants were embedded in completely remodelled bone tissue with very few areas being located in cancellous bone.

\section{Histomorphometry}

There was a significant increase in bone implant contact (BIC) from 1 week to 13 weeks for all implant surfaces ( $p$-values between 0.010 and 0.001 ) (Fig. 5A). Comparison between the individual groups showed that implants with nano-anchored AS and hybridised conjugated rhBMP2 (Group 4) exhibited a mean bone-implant contact (BIC) rate of $21.1 \%$ (SD 7.1) after 1 week. Implants with blank SAE surfaces (Group 1), with SAE surfaces with nano-anchored AS only (Group 2) and SAE surfaces with nano-anchored AS and non-conjugated rhBMP2 (Group 3) showed 13.9\% (SD 3.1), 16.1\% (SD 7.3), and $18.0 \%$ (SD 4.4), respectively. Differences were significant between the groups $(p=0.045)$. Volume of newly formed bone inside the perforations increased significantly from 1 week to 13 weeks only for the implant with SAE surface (Group 1: $p=0.023$ ) (Fig. 5B). After 1 week, bone formation in the perforations had occupied $10.0 \%$ (SD 6.7) of the area in implants with nano-anchored AS and hybridised conjugated rhBMP2 (Group 4) as compared to 4.8 (SD 2.9) in implants with SAE (Group 1), $5.7 \%$ (SD 3.7), in implants with blank SAE surfaces and AS
(Group 2) and $7.2 \%$ (SD 7.2) in implants with SAE surface with AS and non-conjugated rhBMP2 (Group $3)$, respectively. Differences between group means were significant $(p=0.041)$. After 4 weeks, again implants with nano-anchored AS and conjugated rhBMP2 exhibited the highest BIC (54.1\% (SD 8.8)) compared with implants from Groups 3, 2 and 1 showing 46.8 (SD 8.1), $42.5 \%$ (SD 15.5) and $45.11 \%$ (SD .6), respectively $(p=0.029)$. Bone formation inside the perforations was not significantly different in the groups. After 13 weeks, no significant differences could be found between bone implant contact and bone volume in the perforations between the different groups). Peri-implant bone density ranged between $28.2-39.3 \%$ after 1 week and increased to $30.6-40.2 \%$ after 1 month and 39.7-40.5\% after 13 weeks (Fig. 5C). The increase over time was not significant and no significant difference was found between the groups at the three different intervals.

\section{Discussion}

The use of a modular system for the immobilisation of biologically active molecules on biomaterials surfaces using nano-anchored oligonucleotides has been shown to be effective in previous in vitro studies (Michael et al., 2009; Beutner et al., 2009). Moreover, when bone 

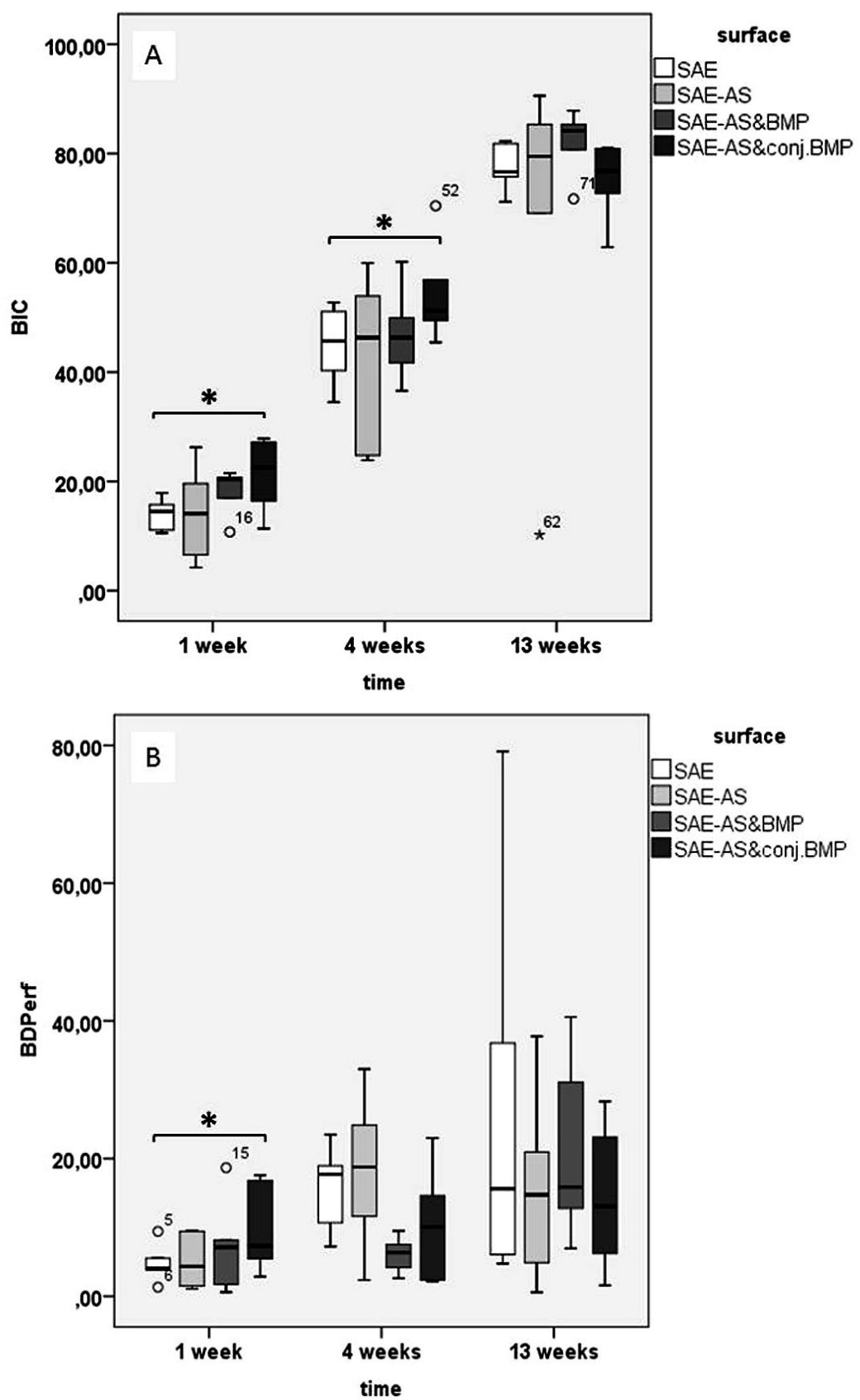

Fig. 5. Boxplots of histomorphometric results of A: Bone-Implant-Contact; B: Bone formation inside perforations; C: Peri-implant bone density. $n=6$; median, box: lower (25)-upper (75) quartile, whiskers: lower and upper 1.5 interquartile range (1.5 IQR); ${ }^{*} p<0.05$.

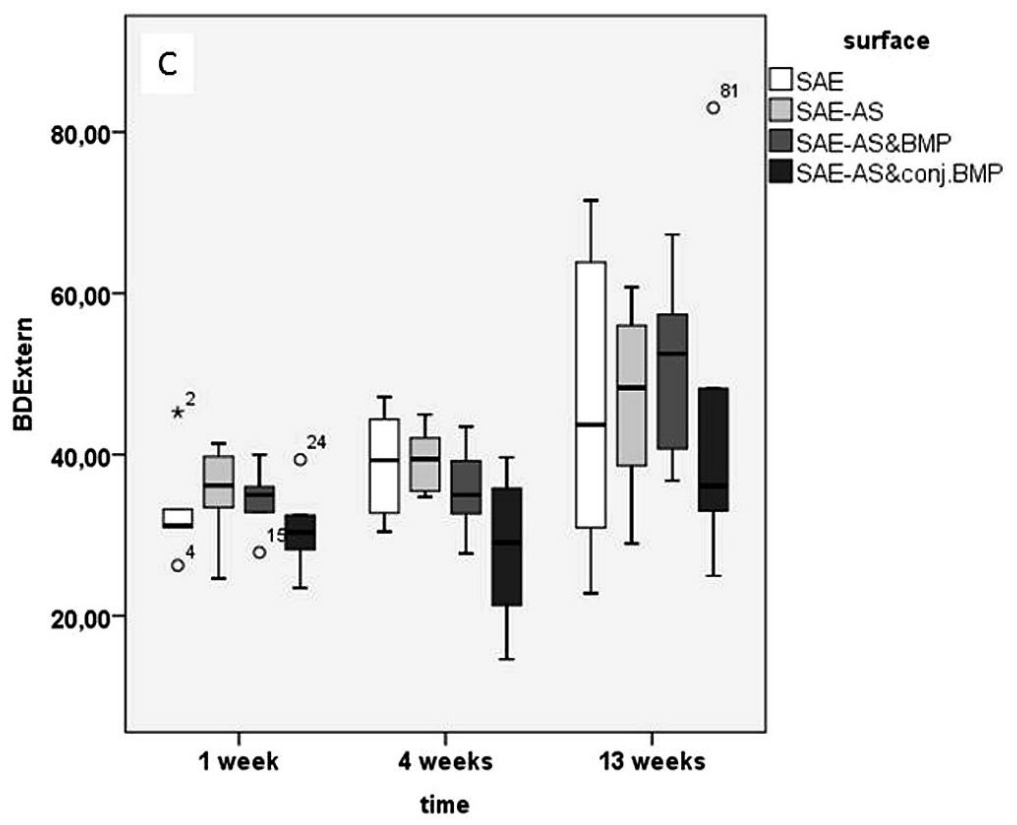


growth factors were tested, the amount of growth factors bound to the titanium surface was significantly increased and the release was significantly retarded when compared to binding of growth factors by simple adsorption (Schliephake et al., 2012a; 2012b). As the binding is accomplished by self-assembly of oligonucleotides and ODN conjugated growth factors through hybridisation, the correct alignment of the oligonucleotides is based on the integrity of the ODN anchor strands. This may be jeopardised by sterilisation. It was thus the aim of this study was to i) develop an easy to use sterilisation process that eliminates pathogens without compromising the performance of the anchor strands (AS) for hybridisation with complementary oligonucleotide strand (CS) and ii) to test this system for its ability to enhance peri-implant bone formation in vivo.

The in vitro results have shown that air-dried samples sterilised in air under normal humidity showed a complete loss of the hybridisation ability of partially incorporated AS after sterilisation. This effect is most likely accounted for by DNA strand breaks, which increase with a higher irradiation dosage (Cai et al., 2006). Studies have shown that DNA adsorbed on a surface has been less sensitive to this effect than DNA dissolved in solution (Demanèche $e t$ al., 2001; Ciaravella et al., 2004). However, the protective effect of adsorption to a titanium surface in the present study appeared to be too small to preserve the strand integrity. Drying of the samples for $48 \mathrm{~h}$ over phosphorus pentoxide and packing in protective atmosphere (argonethanol-atmosphere) has shown the strongest protective effect without addition of sacrificial strands. The positive effect of drying is most likely based on the removal of water, which is known to increase the ionisation potential of the DNA-bases (Kim et al., 1996; La Vere et al., 1996). Additional effects would be the decrease in concentration of reactive oxygen species around the DNA by the argonatmosphere as well as the protective effect of ethanol. In addition, the $\mathrm{OH}$-radical is short-lived but highly reactive and has to occur in close proximity to the DNA molecules to cause damage (Piedade et al, 2006). Therefore a strong drying should show a protective effect (Tran et al., 2004; Grieb et al., 2002). This goes in line with Grieb et al. (2005), who demonstrated the effectivity of freeze-drying to reduce the formation and motility of $\mathrm{OH}$-radicals as a protective measure. The protective effect of ethanol can be explained by the observation of Spotheim-Maurizot et al. (1995) who showed a positive effect of scavengers in preserving DNA integrity by catching the reactive oxygen species before they can react with DNA.

The protective effect of environmental conditions has been even more enhanced by the use of sacrificial strand sequences (SCS). The potential of the SCS to protect the incorporated AS against degradation during the sterilisation process has varied considerably depending on the SCS type and surface concentration as well as the environmental atmosphere. The positive effect of SCS on the AS ability for hybridisation after sterilisation may be based on the same principle as the protective effect of proteins for DNA by causing a dense packing of the DNA and induce a higher radiation resistance by precluding the hydrogen atom on 5 position of the base which is especially sensitive to attacks by OH-radicals (Begusova et al., 2000; Valota et al., 2003). This protective effect has even been considerably increased by increasing the concentration of SCS1. However, when the SCS1-addition was raised to $32.5-35.5 \mathrm{pmol} / \mathrm{cm}^{2}$, the strands competed with the incorporated AS during hybridisation, which necessitated a removal step before hybridisation. The enhanced protection of the high concentration of SCS1 in combination with a wet Argon atmosphere has been also achieved with the lower SCS1 concentration when used in combination with a dry argon-atmosphere. For this reason, set no. 7 has been selected for sterilisation of the implants used in the in vivo experiments.

The SCS2 strands applied with a surface concentration of $56 \mathrm{pmol} / \mathrm{cm}^{2}$ did not provide a convincing degree of protection, despite their high density. A reason for this unexpected effect may be that SCS1 and SCS2 differ in their length and, hence, may differ in conformation under the experimental conditions used. Goddard et al. (2000) showed that short single strand areas (8-30 bases) have a sequence-dependent conformational dynamics (Goddard et al., 2000). The end-to-end length is decreasing in a single DNA-strand after the length exceeds 40 bases as the polymer properties dominate the conformation (Walker et al., 1998; Castelino et al., 2005). Therefore, the SCS1 should have a higher flexibility and could form a denser layer on the surface - in contrast to the SCS2, which had less possible conformations. This could have reduced the electron capture and thus the protecting effect of the SCS (Leforestier et al., 1993; Ray et al,. 2005). In summary, the use of small amounts of sacrificial ODN strands in combination with a dry argon-atmosphere has been able to protect the hybridisation ability of ODN anchor strands, during effective sterilisation of the implants with $25 \mathrm{kGy}$ gamma irradiation.

The aim of the in vivo part of the present study, was to test the ability of this system of controlled binding and release of rhBMP2 for its ability to enhance periimplant bone formation under in vivo conditions. When implants are coated with bone growth factors, peri-implant bone formation can be enhanced through induction of bone formation in the regenerating tissue surrounding the implant surface, on the one hand. This would be predominantly mediated by the portion of growth factor released from the implant surface and result in increased peri-implant bone density. On the other hand, bone cells are recruited to the implant surface by gradients of released growth factors which would enhance the bone implant contact. Evaluation of peri-implant bone density at a distance of $200 \mu \mathrm{m}$ from the surface has shown that there was a parallel increase in all four groups over time but no differences between the groups at any of the intervals. This suggests that the character of the surface as well as the mode of BMP loading and release did not significantly enhance the volume of bone formation in the vicinity of the implant. This appears to be contradictory to the fact that BIC has been significantly increased after 1 week and 1 month. The histologic features, however, indicate that the newly formed bone layers in contact with the implant surface have been very thin and did not significantly add to the peri-implant bone volume. The findings suggest that 
the amount of both non-conjugated and conjugated BMP2 released from the surfaces was too small to induce bone formation in the vicinity of the implants. However, the amount of BMP2 remaining on the surface in the group of implants with conjugated rhBMP2 may have recruited undifferentiated cells to the implant surface, through a slower and continuous release and increased osteogenic differentiation through the larger amount of BMP2 retained on the surface. This would have resulted in formation of a thin bone layer in immediate contact with the implant surface. This would be in line with the observation from previous in vitro studies that rhBMP2 is maintained longer on the implant surface and enhances both proliferation and early osteogenic differentiation of human mesenchymal stem cells grown on the surface (Schliephake et al., 2012a). The morphometric data of the present study, indicate that it is merely early bone formation that is enhanced because there was no difference in any of the assessed parameters after 13 weeks of implantation. The features seen in implants with SAE and SAE \& AS surface indicate that bone formation at the implant surface follows a different pattern without BMP bound to the surface.

In general, it is obvious that differences between results in the different groups at each interval appeared to be small. Part of this effect may be explained by the fact that bone conditions for this experiment were uncompromised. The morphologic and morphometric data indicate that the biological effect of the nano-anchored BMP signals appears to be mainly confined to the cell layers on the implant surface, with a small range of action. As the concentration gradient is important for the function of BMPs in tissue development, the distance from the implant surface up to which the growth factors are effective will be a matter of dosage deposited on the surface. A previous in vitro evaluation had shown that approximately $335 \mathrm{ng} / \mathrm{cm}^{2}$ rhBMP2 can be nano-anchored to the surface (Schliephake et al., 2012a). A previous in vivo study had shown that a constant release of $>100 \mathrm{ng} / 72 \mathrm{~h}$ is required to induce ectopic bone formation (Gruber et al., 2009). Moreover, burst release from soak loaded collagen carriers between $1 \mu \mathrm{g}$ and $10 \mu \mathrm{g}$ of BMP would be necessary for successful ectopic bone induction (Arosarena et al., 2005; Winn et al., 1999). A recent study using polyelectrolyte multilayer films to accommodate BMP2 on the surface of titanium implants had shown that a release between 4 and $14 \mu \mathrm{g}$ successfully induced ectopic bone formation in rodents (Guillot et al., 2013). The dosages released from the present implants into peri-implant tissue fall short of these amounts and thus suggest that the released amount of rhBMP2 from the titanium surfaces equipped with ODN anchor strands is too small to independently induce sustainable bone formation in the peri-implant regenerating tissue, as the level of native osteogenic signalling in this rodent model of non-compromised bone biology is high enough to maintain osteogenesis on its own.

In this way the results correspond to those of previous studies in which small amounts of BMP2 were anchored to and released from titanium implants without being able to increase peri-implant bone density compared to implants coated with the carrier alone (Schliephake et al., 2005, 2009; Stadlinger et al., 2008; Ramazanoglu et al., 2011).
In contrast to these reports, however, the present study suggests that rhBMP2 hybridised to nano-anchored ODN strands on titanium surfaces appears to be effective because of the portion of growth factor attached to the surface by cells recruited to the surface and enhancing bone implant contact.

\section{Conclusions}

Binding of growth factors to titanium surfaces through nano-anchored ODN strands may be jeopardised by sterilisation using gamma irradiation. The present study has shown that deprivation of water as well as the sterilisation in a dry argon-ethanol-atmosphere, in combination with the application of the sacrificial ODN strands, allowed for maintenance of up to $80 \%$ of the hybridisation ability of nano-anchored ODN strands. Using this process for sterilisation of titanium implants has maintained the functionality of this modular system for binding of rhBMP2 to the implant surface. rhBMP2 hybridised to nano-anchored ODN strands on the implant surface has been effective in vivo through the portion of growth factor attached to the surface by enhancing bone implant contact.

\section{Acknowledgements}

The authors greatly value the help of Mrs. Jutta Schulz during the laboratory experiments. This work has been funded by grants from the Federal Ministry of Education and Research (BMBF) (No. 13N10006) and the DFG (SCHL368/11-1).

We thank Dr. Steffen Taut and his team of the Central Radionuclide Laboratory of the TU Dresden for providing the analysis facilities and methodical support.

\section{References}

Adden N, Gamble LJ, Castner DG, Hoffmann A, Gross G, Menzel H (2006a) Phosphonic acid monolayers for binding of bioactive molecules to titanium surfaces. Langmuir 22: 8197-8204.

Adden N, Gamble LJ, Castner DG, Hoffmann A, Gross G, Menzel H (2006b) Synthesis and characterization of biocompatible polymer interlayers on titanium implant materials. Biomacromolecules 7: 2552-2559.

Arosarena O, Collins W (2005) Comparison of BMP2 and -4 for rat mandibular bone regeneration at various doses. Orthod Craniofac Res 8: 267-276.

Begusova M, Charlier M, Spotheim-Maurizot M (2000) Radiolysis of nucleosome core DNA: a modelling approach. Int J Radiat Biol 76: 1063-1073.

Beidas OE, Deschamps-Braly JC, Morgan AM, Workman MC, Knotts CD, Denny AD, El Amm CA (2013) Safety and efficacy of recombinant human bone morphogenetic protein 2 on cranial defect closure in the pediatric population. J Craniofac Surg 24: 917-922.

Beutner R, Michael J, Förster A, Schwenzer B, Scharnweber D (2009) Immobilization of oligonucleotides 
on titanium based materials by partial incorporation in anodic oxide layers. Biomaterials 30: 2774-2781.

Cai Z, Dextraze ME, Cloutier P, Hunting D, Sanche L (2006) Induction of strand breaks by low-energy electrons (8-68 eV) in a self-assembled monolayer of oligonucleotides: effective cross sections and attenuation lengths. J Chem Phys 124: 024705.

Castelino K, Kannan B, Majumdar A (2005) Characterization of grafting density and binding efficiency of DNA and proteins on gold surfaces. Langmuir 21: 19561961.

Choi GH, Lee HJ, Lee SC (2014) Titanium-adhesive polymer nanoparticles as a surface-releasing system of dual osteogenic growth factors. Macromol Biosci 14: 496-507.

Ciaravella A, Scappini F, Franchi M, Cecchi-Pestellini C, Barbera M, Candia R, Gallori E, Micela G (2004) Role of clays in protecting adsorbed DNA against X-ray radiation. Int J Astrobiol 3: 31-35.

Demanèche S, Jocteur-Monrozier L, Quiquampoix H, Simonet P (2001) Evaluation of biological and physical protection against nuclease degradation of clay-bound plasmid DNA. Appl Environ Microbiol 67: 293-299.

Donath K (1985) The diagnostic value of the new method for the study of undecalcified bones and teeth with attached soft tissue (Sage-Schliff (sawing and grinding) technique). Pathol Res Pract 179: 631-633.

Goddard NL, Bonnet G, Krichevsky O, Libchaber A (2000) Sequence dependent rigidity of single stranded DNA. Phys Rev Lett 85: 2400-2403.

Grieb T, Forng RY, Brown R, Owolabi T, Maddox E, Mcbain A, Drohan WN, Mann DM, Burgess WH (2002) Effective use of gamma irradiation for pathogen inactivation of monoclonal antibody preparations. Biologicals 30: 207-216.

Grieb TA, Forng RY, Stafford RE, Lin J, Almeida J, Bogdansky S, Ronholdt C, Drohan WN, Burgess WH (2005) Effective use of optimized, high dose (50 kGy) gamma irradiation for pathogen inactivation of human bone allografts. Biomaterials 26: 2033-2042.

Gruber RM, Weich H, Dullin C, Schliephake H (2009) Ectopic bone formation after implantation of a slow release system of polylactid acid and rhBMP2. Clin Oral Implants Res 20: 24-30.

Guillot R, Gilde F, Becquart P, Sailhan F, Lapeyrere A, Logaert-Avramoglou D, Picart C (2013) The stability of BMP loaded polyelectrolyte coated multilayer coating on titanium. Biomaterials 34: 5737-5746.

Keller JC, Stewart M, Roehm, M, Schneider GB (2004) Osteoporosis-like bone conditions affect osseointegration of implants. Int J Oral Maxillofac Implants 19: 687-694.

Kim SE, Yun YP, Lee JY, Shim JS, Park K, Huh JB (2013) Co-delivery of platelet-derived growth factor (PDGF-BB) and bone morphogenetic proetin (BMP-2) coated onto heparinized titanium for improving osteoblast function and osteoinegration. J Tissue Eng Regen Med; doi:10.1002/term1668.

Kim SE, Sing SH, Yun YP, Choi BJ, Kwon IK, Bae MS, Moon HJ, Kwon YD (2011) The effect of immobilization of heparin and bone morphogenetic protein-2 (BMP-2) to titanium surfaces on inflammation and osteoblast function. Biomaterials 32: 366-373.
Kim S, Lee W, Herschbach D (1996) Cluster beam chemistry: hydration of nucleic acid bases; ionization potentials of hydrated adenine and thymine. J Phys Chem 100: 7933-7937.

La Vere T, Becker D, Sevilla M (1996) Yields of 'OH in gamma-irradiated DNA as a function of DNA hydration: hole transfer in competition with ' $\mathrm{OH}$ formation. Radiat Res 145: 673-680.

Lee DW, Yun YP, Park K, Kim SE (2012) Gentamicin and bone morphogenic protein-2 (BMP-2)-delivering heparinized-titanium implant with enhanced antibacterial activity and osteointegration. Bone 50: 974-982.

Leforestier A, Livolant F (1993) Supramolecular ordering of DNA in the cholesteric liquid crystalline phase: an ultrastructural study. Biophys J 65: 56-72.

Leknes KN, Yang J, Qahash M, Polimeni G, Susin C, Wikesjö UM (2008) Alveolar ridge augmentation using implants coated with recombinant human bone morphogenetic protein-2: radiographic observations. Clin Oral Implants Res 19: 1027-1033.

Leknes KN, Yang J, Qahash M, Polimeni G, Susin C, Wikesjö UM (2013) Alveolar ridge augmentation using implants coated with recombinant human growth/ differentiation factor 5 (rhGDF-5). Radiographic observations. Clin Oral Implants Res 24: 1185-1191.

McCracken M, Lemons JE, Rahemtulla F, Prince CW, Feldman D (2000) Bone response to titanium alloy implants placed in diabetic rats. Int J Oral Maxillofac Implants 15: 345-354.

Merrick MT, Hamilton KD, Russo SS (2013) Acute epidural lipedema: a novel entity and potential complication of bone morphogenetic protein use in lumbar spine fusion. Spine J 13: e15-19.

Michael J, Schönzart L, Israel I, Beutner R, Scharnweber D, Worch H, Hempel U, Schwenzer B (2009) Oligonucleotide-RGD peptide conjugates for surface modification of titanium implants and improvement of osteoblast adhesion. Bioconjug Chem 20: 710-718.

Muchow RD, Hsu WK, Anderson PA (2010) Histopathologic inflammatory response induced by recombinant bone morphogeneticprotein-2 causing radiculopathy after transforaminal lumbar interbody fusion. Spine J 10: e1-6.

Mueller CK, Thorwarth M, Schmidt M, Schlegel KA, Schultze-Mosgau S (2011) Comparative analysis of osseointegration of titanium implants with acid-etched surfaces and different biomolecular coatings. Oral Surg Oral Med Oral Pathol Oral Radiol Endod 112: 726-736.

Pan J, Shirota T, Ohno K, Michi K (2000) Effect of ovariectomy on bone remodeling adjacent to hydroxyapatite-coated implants in the tibia of mature rats. J Oral Maxillofacial Surg 58: 877-882.

Piedade JA, Oliveira PS, Lopes MC, Oliveira-Brett AM (2006) Voltammetric determination of gamma radiationinduced DNA damage. Anal Biochem 355: 39-49.

Ramazanoglu M, Lutz R, Ergun C, von Wilmowsky C, Nkenke E, Schlegel KA (2011) The effect of combined delivery of recombinant human bone morphogenetic protein-2 and recombinant human vascular endothelial growth factor 165 from biomimetic calcium-phosphate 
coated implants on osseointegration. Clin Oral Implants Res 22: 1433-1439.

Ramazanoglu M, Lutz R, Rusche P, Trabzon L, Kose GT, Prechtl C, Schlegel KA (2013) Bone response to biomimetic implants delivering BMP-2 and VEGF: an immunohistochemical study. J Craniomaxillofac Surg 41: 826-835.

Ray SG, Daube SS, Naaman R (2005) On the capturing of low-energy electrons by DNA. Proc Natl Acad Sci USA 102: $15-19$.

Schliephake H, Bötel C, Förster A, Schwenzer B, Reichert J, Scharnweber D (2012a) Effect of oligonucleotide mediated immobilization of bone morphogenic proteins on titanium surfaces. Biomaterials 33: 1315-1322.

Schliephake H, Strecker N, Förster A, Schwenzer B, Reichert J, Scharnweber D (2012b) Angiogenic functionalisation of titanium surfaces using nano-anchored VEGF - an in vitro study. Eur Cell Mater 23: 161-169.

Schliephake H, Aref A, Scharnweber D, Bierbaum S, Roessler S, Sewing A (2005) Effect of immobilized bone morphogenic protein 2 coating of titanium implants on peri-implant bone formation. Clin Oral Implants Res 16: 563-569.

Schliephake H, Aref A, Scharnweber D, Bierbaum S, Sewing A (2009) Effect of modifications of dual acidetched implant surfaces on peri-implant bone formation. Part I: Organic coatings Clin Oral Implants Res 20: 31-37.

Shweikeh F, Hanna G, Bloom L, Sayegh ET, Liu J, Acosta FL, Drazin D (2014) Assessment of outcome following the use of recombinant human bone morphogeneticprotein-2 for spinal fusion in the elderly population. J Neurosurg Sci [Epub ahead of print].

Spotheim-Maurizot M, Ruiz S, Sabattier R, Charlier M (1995) Radioprotection of DNA by polyamines. Int J Radiat Biol 68: 571-577.

Stadlinger B, Pilling E, Huhle M, Mai R, Bierbaum S, Scharnweber D, Kuhlisch E, Loukota R, Eckelt U (2008) Evaluation of osseointegration of dental implants coated with collagen, chondroitin sulphate and BMP-4: an animal study. Int J Oral Maxillofac Surg 37: 54-59.

Thorey F, Menzel H, Lorenz C, Gross G, Hoffmann A, Windhagen H (2011) Osseointegration by bone morphogenetic protein-2 an transforming growth factor beta 2 coated titanium implants in femora of New Zealand white rabbits. Indian J Orthop 45: 57-62.

Tran H, Marlowe K, McKenney K, Petrosian G, Griko Y, Burgess WH, Drohan WN, Imboden MA, Kempf C, Boschetti N, Mann DM (2004) Functional integrity of intravenous immunoglubin following irradiation with a virucidal dose of gamma radiation. Biologicals 32: 94-104.
Valota A, Ballarini F, Friedland W, Jacob P, Ottolenghi A, Paretzke HG (2003) Modelling study on the protective role of $\mathrm{OH}$ radical scavengers and DNA higher-order structures in induction of single-and double-strand break by gamma-radiation. Int J Radiat Biol 79: 643-653.

Walker H, Grant S (1998) Influence of surface charge and particle size on the stabilization of colloidal particles by model polyelectrolytes. Colloid Surface A 135: 123-133.

Wikesjö UM, Qahash M, Polimeni G, Susin C, Shanaman RH, Rohrer MD, Wozney JM, Hall J (2008) Alveolar ridge augmentation using implants coated with recombinant human bone morphogenetic protein-2: histologic observations. J Clin Periodontol. 35: 1001-1010.

Winn SR, Uludag H, Hollinger JO (1999) Carrier systems for bone morphogenetic proteins. Clin Orthop Relat Res 367S: S95-S106.

Zheng D, Neoh KG, Shi Z, Kang ET (2013) Assessment of stability of surface anchors for antibacterial coatings and immobilized growth factors on titanium. J Colloid Interface Sci 406: 238-246.

\section{Discussion with Reviewers}

Reviewer I: What is the anticipated mechanism of release of ODN-conjugated, immobilised BMP in vivo? How would endonuclease activity (a common issue also for naked DNA gene delivery in gene therapy) impact on BMP immobilisation in vivo?

Authors: The mechanism of release will most likely be dissociation of DNA double strands. Preliminary experiments studying the stability of the ODN based immobilisation system in cell culture medium did not show any signs on endonuclease activity with respect to a release from the substrate surface. This might be caused by steric hindrance of endonuclease activity due close proximity to the substrate surface. This situation may however change if longer DNA sequences are used for immobilisation and will presumably affect the complementary ODN strands after dissociation of hybridised rhBMP2-conjugates.

Reviewer I: Would autoclaving be another viable sterilisation approach for the devised system as DNA is relatively heat-resistant?

Authors: Heat sterilisation has been investigated using standard conditions for autoclaving $\left(121^{\circ} \mathrm{C}\right.$ for $\left.15 \mathrm{~min}\right)$. This resulted in a complete removal of hybridisation ability.

Editor's Note: Scientific Editor in charge of the paper: Christine Hartman. 